\title{
ДИСЦИПЛИНЫ ЗДОРОВЬЕСБЕРЕГАЮЩЕЙ НАПРАВЛЕННОСТИ КАК СРЕДСТВО ФОРМИРОВАНИЯ КУЛЬТУРЫ ЗДОРОВОГО ОБРАЗА ЖИЗНИ СТУДЕНТОВ В ПЕДАГОГИЧЕСКОМ УНИВЕРСИТЕТЕ
}

\section{HEALTH SAVING DISCIPLINES AS A MEANS OF CREATING A CULTURE OF HEALTHY LIVING FOR STUDENTS AT THE PEDAGOGICAL UNIVERSITY}

\section{S. Kuptsova}

Summary: The rapid pace of development of modern society is characterised by the digitalisation of all spheres of life, environmental disasters, pandemics, a decline in the adaptive capacity of the human body and the emergence of new diseases. Therefore, the formation of a culture of healthy lifestyles is one of the leading tasks of modern educational institutions. At the Pedagogical University, the key role in developing a culture of a healthy lifestyle is played by health-oriented disciplines. In this regard, the article analyzes the concepts of "a healthy lifestyle", "culture of a healthy lifestyle" and "health saving technologies" and presents the results of a survey of students, forms of classes organisation and content of training materials. Lecturing and practical classes, independent work of students are aimed at forming a strong motivation for a healthy lifestyle, culture of health and, ultimately, at improving the quality of education at the university.

Keywords: health saving discipline, culture of healthy way of life, pedagogical university.

\author{
Купцова Светлана Анатольевна \\ К.п.н., доцент, Российский государственный \\ педагогический университет \\ им. А.И. Герцена, г. Санкт-Петербург) \\ kupsv@yandex.ru
}

Аннотация: Стремительный темп развития современного общества характеризуется цифровизацией всех сфер жизнедеятельности, экологическими катастрофами, пандемиями, снижением адаптационных возможностей организма человека, появлением новых болезней. Поэтому формирование культуры здорового образа жизни - одна из ведущих задач современных образовательных учреждений. В педагогическом университете ключевую роль в формировании культуры здорового образа жизни играют дисциплины здоровьесберегающей направленности. В связи с этим в статье проанализированы понятия «здоровый образ жизни», «культура здорового образа жизни» «здоровьесберегающие технологии»; представлены результаты анкетирования студентов; формы организации занятий и содержание учебных материалов дисциплин в сфере здоровьесбережения. Лекционные и практические занятия, самостоятельная работа студентов направлены на формирование стойкой мотивации к здоровому образу жизни, культуры здоровья и в конечном итоге на повышение качества образования в вузе.

Ключевые слова: дисциплины здоровьесберегающей направленности, культура здорового образа жизни, педагогический университет.

$9,10]$. В вузе важно использовать различные средства актуализации ценностных установок у студентов в сфере здорового образа жизни, формировать готовность к ведению здорового образа жизни, способствовать овладению ими здоровьесберегающими технологиями для работы в различных социальных сферах [11]. Одним из ключевых средств формирования культуры здорового образа жизни в педагогическом университете является разработка различных учебных дисциплин, ориентированных на поддержание и развитие здоровья [11] с учетом особенностей, потребностей и профессионального самоопределения современного поколения (поколения Z) $[12,13,14]$.

Цель исследования - рассмотреть основные понятия исследуемой темы; проанализировать результаты анкетирования студентов; представить формы организации занятий, содержание учебных материалов, педагогические условия для формирования культуры здоро- 
вого образа жизни студентов в университете.

\section{Методы исследования.}

Наблюдение и анкетирование. Данные методы позволили определить круг вопросов, которые возникли при формировании культуры здорового образа жизни студентов.

Эксперимент. Во время проведения занятий экспериментально были апробированы различные формы организации занятий и способы формирования культуры здорового образа жизни.

Анализ. Во время наблюдения, анкетирования и эксперимента проводился анализ поступающей информации с целью определения формы организации занятий, содержания учебных материалов и педагогических условий формирования культуры здорового образа жизни обучающихся.

\section{Результаты исследования.}

Большинством исследователей здоровый образ жизни определяется как концепция жизнедеятельности человека, включающая систему рационального питания, физическую подготовку, отсутствие вредных привычек, умение управлять собой, своими эмоциями $[15,16,17]$.

По современным представлениям, ведущими составляющими здорового образа жизни является образование в области педагогики и психологии здоровья как неотъемлемой части современного образования и культуры человека $[15,16,17]$.

Культура здорового образа жизни понимается как часть общей культуры человека, включающая знания о здоровье, мотивационно-ценностные установки и поведенческую активность в направлении здоровьесохранения и здоровьесозидания $[15,18,19]$.

К критериям культуры здорового образа жизни (ЗОЖ) относят:

- показатели различных уровней здоровья (в т. ч. уровня адаптации к условиям среды);

- степень сформированности установки на здоровый образ жизни и знаний в сфере здоровья;

- уровень усвоения практических навыков по поддержанию и укреплению здоровья;

- умение самостоятельно построить индивидуальную траекторию здоровья и программу 30Ж [15, $16,17]$.

Формирование культуры здорового образа жизни у студентов связано с овладением ими здоровьесберегающими технологиями для работы в различных социальных сферах.
Анализируя здоровьесберегающие технологии, можно выделить ряд особенностей их использования в образовательном процессе:

- учет индивидуальных и возрастных возможностей обучающихся;

- использование двигательной активности;

- профилактика деструктивной организации педагогического процесса [20, 21, 22];

Критериями эффективности здоровьесберегающих технологий и их реализации в образовательном процессе являются:

- психофизиологический критерий, свидетельствующий о функциональном состоянии участников образовательного процесса;

- личностный критерий, свидетельствующий о мотивационном, эмоциональном, когнитивном состоянии обучающихся;

- практический критерий (физический, этический, творческий, воспитательный) - свидетельствующий о степени нравственного благополучия субъектов образования;

- педагогический критерий, свидетельствующий о качестве функционирования ОС (образовательная система школы / СПО / ВУЗа) [20, 22, 23].

Экспертиза целесообразности использования здоровьесберегающих технологий обеспечивается медикопсихолого-педагогическим мониторингом.

Изучение студентами теории и практики здорового образа жизни, здоровьесберегающих технологий в педагогическом университете необходимо для дальнейшей работы в педагогической сфере $[11,20]$.

С целью определения форм организации занятий, содержания учебных материалов, педагогических условий формирования культуры здорового образа жизни обучающихся, мы провели анкетирование. В результате были получены следующие данные: понятие «здоровье» студенты связывают в большей степени с физическим уровнем (общее физическое состояние здоровья, отсутствие болезней) и психическим уровнем (умение контролировать свои эмоции, стрессоустойчивость).

Здоровый образ жизни ассоциируется со здоровым (рациональным) питанием, соблюдением режима сна, занятиями физической культурой и спортом, ежедневным пребыванием на свежем воздухе, грамотным чередованием учёбы и отдыха.

Обучающиеся отметили, что информацию о здоровом образе жизни, навыки организации ЗОЖ получают из лекционных и практических занятий в университете, а также из социальных сетей.

Студенты указали на необходимость преподавания 
в вузе дисциплин, связанных со здоровьем и здоровым образом жизни.

Согласно проведенному анализу исследуемой проблемы, культура здорового образа жизни обучающихся зависит от содержания и условий организации образовательного процесса в области здоровьесбережения. Ключевым звеном в формировании культуры здорового образа жизни выступает изучение дисциплин здоровьесберегающей направленности. В данном направлении реализуются следующие дисциплины: «Основы здорового образа жизни», «Здоровьесберегающие технологии», «Социально-педагогический тренинг», «Духовно-нравственное воспитание детей и подростков» и др.

В качестве примера приведем содержание дисциплины «Основы здорового образа жизни» (дисциплина разработана на факультете Безопасности жизнедеятельности РГПУ им. А.И. Герцена (кафедра медико-валеологических дисциплин)).

\section{Темы теоретических и практических занятий:}

1. Понятие о здоровье и здоровом образе жизни. Понятие о здоровье и культуре здоровья как одной из составляющих общей культуры человека. Отбор содержания основ здорового образа жизни. Методологические основы здорового образа жизни. Принципы и основные задачи дисциплины.

2. Основы системной профилактики саморазрушающего поведения человека. Понятия «саморазрушающее поведение», «профилактика отклоняющегося поведения». Системная профилактика как основа культуры здорового образа жизни.

3. Контроль индивидуального здоровья - как ценностный компонент формирования здорового образа жизни. Личное поведение человека - одно из стратегических направлений профилактической медицины. Условия, обеспечивающие эффективность профилактических мероприятий. Оценка индивидуального здоровья с помощью клиникобиохимических показателей и различных тестов. Контроль индивидуального здоровья. Общественное здоровье и его критерии.

4. Психология здоровья Понятия психического и психологического здоровья. Меры по профилактике психических расстройств. Стресс и дистресс. Методы коррекции психоэмоционального состояния.

5. Физическое здоровье и развитие болезней. Физическое здоровье как позитивное состояние. Правила и нормы физической нагрузки. Значение физической нагрузки для функционального равновесия организма.

6. Состояние питания и развитие болезней. Влияние режима питания на развитие болезней. Анализ режима питания современного человека. Оптимальный режим питания людей разных возрастных категорий и трудовых профессий.

\section{ЗаАәния А^я практических занятий и самостоятельной работы стуАентов.}

1. Заполните таблицу «Основные понятия дисциплины».

Таблица 1.

Основные понятия дисциплины.

\section{\begin{tabular}{|l|l|}
\hline$№ n / п$ & Основные понятия \\
\hline
\end{tabular}}

1. Здоровье - это (определение, автор, источник, ссылка). Проанализировать не менее 3 определений понятия.

2. Здоровый образ жизни - это (определение, автор, источник, ссылка). Проанализировать не менее 3 определений понятия.

3. Культура здоровья - это (определение, автор, источник, ссылка).

Проанализировать не менее 3 определений понятия.

2. Составьте каталог образовательных сайтов с дополнительной информацией по теме «Понятие о здоровье и здоровом образе жизни».

3. Подготовьте видеоряд / презентацию по профилактике саморазрушающего поведения (на примере одной из возрастных групп обучающихся).

4. Представьте систему мероприятий по профилактике саморазрушающего поведения (на примере Вашего образовательного учреждения) (в виде доклада / презентации).

5. Заполните схему «Условия, обеспечивающие эффективность профилактическихмероприятий» (на примереоднойизвозрастныхгруппобучающихся).

Схема 1.

Условия, обеспечивающие эффективность профилактических мероприятий (на примере одной из возрастных групп обучающихся).

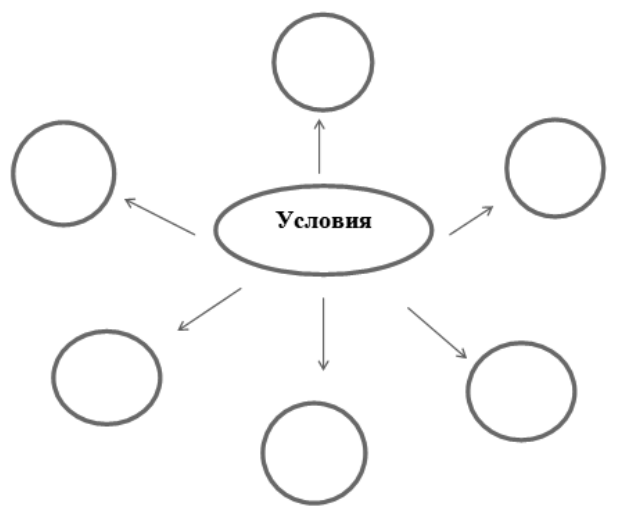

6. Представьте в виде доклада / презентации систему мероприятий по профилактике нарушений 
психических состояний.

7. Подготовьте презентацию / доклад на тему «Учебные стрессы, их проявление и коррекция».

8. Заполните таблицу «Методы профилактики стрессовых состояний».

Таблица 2.

Методы профилактики стрессовых состояний.

\begin{tabular}{|c|c|c|c|}
$\begin{array}{c}\text { № } \\
\text { п/п }\end{array}$ & $\begin{array}{c}\text { Методы } \\
\text { профилактики }\end{array}$ & $\begin{array}{c}\text { Краткая } \\
\text { характеристика }\end{array}$ & $\begin{array}{c}\text { Область } \\
\text { применения }\end{array}$ \\
\hline 1. & & & \\
\hline 2. & & & \\
\hline 3. & & & \\
\hline 4. & & & \\
\hline 5. & & & \\
\hline
\end{tabular}

9. Подготовьте видеоряд / презентацию по теме «Профилактика нарушений физического здоровья».

10. Подготовьте доклад / презентацию на тему «Значение оздоровительной физической культуры для обучающихся разных возрастных групп».

11. Подготовьте презентацию по типам питания человека и влияния на здоровье.

Для выполнения практических заданий и самостоятельной работы (групповая и индивидуальная формы проведения занятий) в помощь студентам сформулированы методические рекомендации. Все материалы (как лекционные, так и практические) представлены в электронной образовательной среде Moodle. Обучающиеся могут в любое удобное для них время вернуться к лекционному материалу, заданиям. Преподаватели активно поддерживают связь с обучающимися так же в электрон- ной образовательной среде Moodle.

\section{Обсужмение}

В целом можно отметить, что разработка различных учебных дисциплин, ориентированных на поддержание и развитие здоровья, является ключевым средством формирования культуры здорового образа жизни студентов в педагогическом университете.

Важное значение в университете придается созданию оптимальных условий обучения, поддержанию психологически комфортной атмосферы, формированию коммуникативных навыков, развитию навыков самостоятельной работы студентов.

Материалы, применяемые для формирования культуры здорового образа жизни, соответствуют следующим требованиям: легко адаптируются к любой форме обучения (как к очной, так и к дистанционной); обладают достаточной степенью интерактивности; индивидуализированы.

Кроме учебных дисциплин, в университете проводятся общекультурные и просветительские мероприятия (просветительские акции, олимпиады, конкурсы, организовано волонтёрское движение), студенты привлечены к научным исследованиям вопросов здорового образа жизни.

Таким образом, в педагогическом вузе у обучающихся есть возможность овладеть современными здоровьесберегающими технологиями, включиться в деятельность, формирующую ценностное отношение к здоровью, культуру здорового образа жизни.

\section{ЛИТЕРАТУРА}

1. Айдаркин Е.К., Иваницкая Л.Н. Возрастные основы здоровья и здоровьесберегающие образовательные технологии [Текст] / Е.К. Айдаркин, Л. Н. Иваницкая: учеб, пособие. - Ростов н/Д: Изд-во ЮФУ, 2017. - 176 с.

2. Ананьев В.В. Основы психологии здоровья. Книга 1. Концептуальные основы психологии здоровья. - СПб: Речь, 2006. - 384 с.

3. Мархоцкий Я.Л. Валеология: учеб, пособие / Я.Л. Мархоцкий. - 2-е изд. - Минск: Выш. шк., 2016. - 286 с.

4. Брехман И.И. Введение в валеологию - науку о здоровье. - Л.: Наука, 1987. - 125 с.

5. Лисицин Ю.П. Социальная гигиена и организация здравоохранения. - М., 1992. - 512 с.

6. Кувшинов Ю.А., Основы медицинских знаний и здорового образа жизни [Текст]: учебное пособие / Ю.А. Кувшинов. - Кемерово: КемГУКИ, 2015. - 183 с.

7. Комиссарова, Е.Н., Родичкин, П.В., Сазонова, Л.А. Морфологические основы возрастной гигиены, РГПУ, 2015. - 63 с.

8. Куинджи Н.Н. Валеология: Пути формирования здоровья школьников: [Метод. пособие]. - М.: Аспект-пресс, 2001. - 136 с.

9. К Кухта Ю.С. Сущность медико-биологических основ безопасности жизнедеятельности: [Текст]: в 2-х частях: учеб, пособие / Ю.С. Кухта. М.Д. Горбатенков. Новосибирск: Изд-во НГТУ. 2016. - Часть 2. - 120 с.

10. Чижкова М.Б. Особенности нарушения здорового поведения у студентов медицинского университета разных лет обучения // Мир науки. Педагогика и психология, 2020 №1, https://mir-nauki.com/PDF/23PSMN120.pdf

11. Станкевич П.В. Роль педагогического вуза в формировании здорового образа жизни / Станкевич П. В., Макарова Л. П., Авдеева Н. В. // Человек и образование [Текст]. - 2018. - N 4 (57). - С. 153-158.

12. Поняева Т.А. Использование системы Мoodle в дистанционном обучении как основа непрерывного обучения в вузе в условиях пандемии // Успехи 
гуманитарных наук. 2020. № 8. С. 161-163.

13. Богуславский М.В., Неборский Е.В. Перспективные тренды развития российского университетского образования // Традиции и новации в профессиональной подготовке и деятельности педагога. Сборник научных трудов Международной научно-практической конференции. 2019. С. 8-12.

14. Гейбука С.В., Ковшова Ю.Н. Повышение эффективности самостоятельной работы студентов педагогического университета при дистанционном обучении математическим дисциплинам // Мир науки. Педагогика и психология, 2020 №5, https://mir-nauki.com/PDF/15PDMN520.pdf

15. Белова Л.В. Здоровьесберегающие технологии в системе профессионального образования: учебное пособие. - Изд-во: СКФУ, 2015. - 93 с.

16. Здоровый образ жизни как один из аспектов безопасности жизнедеятельности: учебное пособие / Е.В. Чуприна, М.Н. Закирова. - Самара: СГАСУ, 2016. 216 c.

17. Мактамкулова Г.А. Основы психического здоровья [Текст]: курс лекций / Г.А. Мактамкулова - Липецк: Изд-во ЛГту. 2017. - 108 с.

18. Метлякова Л.А. Конфликтология: учеб.-метод, пособие: направления подготовки 44.03 .02 - «Психолого-педагогическое образование» и 39.03 .03 - «0рганизация работы с молодёжью» / Л.А. Метлякова; Перм. гос. туманит. - пед. ун-т. - Пермь, 2016. - 208 с.

19. Хасанова Г.Б. Психофизиология профессиональной деятельности: учебное пособие / Г.Б. Хасанова; Минобрнауки России. Казан. исслед. технол. ун-т. Казань: Изд-во: КНИГУ, 2017.-168 с.

20. Митяева А.М. Здоровьесберегающие педагогические технологии [Текст]: учебное пособие /А.М. Митяева. - М.: Академия, 2015. - 202 с.

21. Основы формирования здоровья детей. Жданова Л.А., Основы формирования здоровья детей [Текст]/ Л.А. Жданова [и др.]; под ред. Л.А. Ждановой - М.: ГЭОТАР-Медиа, 2017. - 416 с.

22. Прохорова Э.М. Валеология [Текст]: Учебное пособие. - Москва: 000 «Научно-издательский центр ИНФРА-М», 2016. - 256 с.

23. Татарникова Л.Г. Педагогика здоровья: здоровьесберегающие образовательные технологии.- СПб: СПб АППО, 2010. - 184 с.

(c) Купцова Светлана Анатольевна (kupsv@yandex.ru).

Журнал «Современная наука: актуальные проблемы теории и практики»

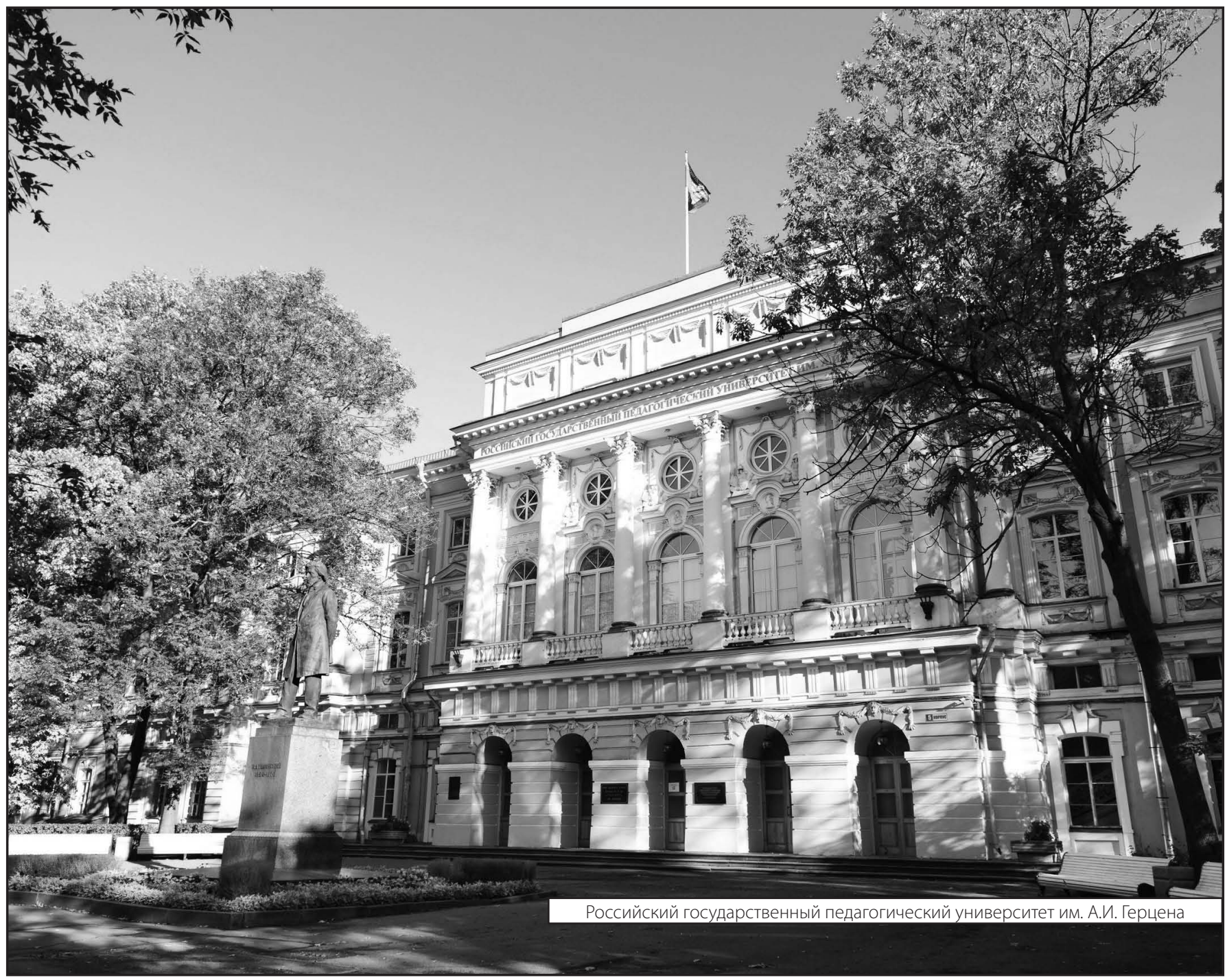

